Perhaps it is wrong to generalise too much from this observation, but it does illustrate just how holistic we 'general' practitioners have to be.

\section{Peter Perkins}

FRCGP, MRCS, Southbourne Surgery, 17 Beaufort Road, Bournemouth, BH6 5BF. Email: peter.perkinsladorset.nhs.uk

\section{REFERENCE}

1. Ansari S, Ford AC. Initial management of dyspepsia in primary care: an evidence-based approach. $\mathrm{Br} J$ Gen Pract 2013; 63(614): 498-499.

\section{DOI: 10.3399/bjgp13X673621}

\section{Future proofing primary care}

In the September issue of the Journal, Tim Ballard wrote: 'The penny dropped with me at the RCGP Annual Conference in Harrogate last year, that the best way of future proofing the healthcare system in the UK is to invest in the education and skills of GPS and their teams, in short, helping them to deliver high quality generalist personalised care. At the heart of this is the skill to deliver bespoke patient care and manage risk without resorting to over-medicalisation and consequent high resource use.'

In the same issue, in an article on dyspepsia in primary care, two gastroenterologists wrote: 'The initial management of uncomplicated dyspepsia in the community should consist of either non-invasive testing for Helicobacter pylori, so-called test and treat', with proton pump inhibitor (PPI)-based triple therapy for those testing positive (PPI and two antibiotics) and 4 weeks of PPI for those testing negative, or empirical PPI for all patients. ${ }^{2}$

The gastroenterologists seem to be teaching us how to cope without an endoscope. Surely, as Ballard's editorial indicated, our scope needs to be wider than this: we have to learn not just about $H$. pylori but also about other causes of abdominal pain, about the low predictive values of tests, about the way symptoms change over time, either improving spontaneously or becoming more clearly defined, and about the power of serial history and examination.

Wilfrid Treasure,
Whalsay, Shetland ZE2 9AE.

E-mail: wilfrid.treasurelanhs.net

\section{REFERENCES}

1. Ballard T. What sustainability means for primary care: primary care leads to better overall resource use and higher quality outcomes. Br J Gen Pract 2013; 53(614): 457-458

2. Ansari S, Ford AC. Initial management of dyspepsia in primary care: an evidence-based approach. $\mathrm{Br} J$ Gen Pract 2013; 63(614): 498-499.

DOI: 10.3399/bjgp13X673630

\section{Response to 'Repeat prescribing = hassle'}

Greenhalgh bemoans the fact that repeat prescribing has become a chore and generated its own bureaucracy. ${ }^{1}$ Much of the hassle is self-inflicted.

My hypertension was diagnosed while was serving in the Army. Once it was brought under control I was reviewed every 6 months and was given a prescription for 6 months supply of medication. On retiring and coming under NHS care, I was still reviewed 6monthly but was only trusted with a month's supply of medication at a time on the basis of PCT guidelines.

I fully understand that some patients cannot manage 6 months' supply of medication and in my days as an NHS GP I emptied older patients' drug cupboards of hoarded drugs

My challenge to you is to regard guidelines as what they really are, practice the personalised, patient-centred care, which you all espouse, and trust those of us who can manage their drugs by prescribing reasonable amounts and go back and enjoy coffee, cake, and the conviviality of an informal meeting with your colleagues and make repeat prescribing less of a chore. Are there any good reasons why you should not?

\section{JPG Bolton,}

Retired GP, Somerset.

\section{REFERENCE}

1. Greenhalgh $\mathrm{T}$. Repeat prescribing $=$ hassle. $\mathrm{Br} \mathrm{J}$ Gen Pract 2013; 63(612): 369

DOI: 10.3399/bjgp13X673649

\section{Persistent cough in children}

Philipson et al have provided more evidence on subclinical Bordetella pertussis infection. After reading the article one could think that $B$. Pertussis was just another, impossible to distinguish, cause of prolonged coughing, that only a laboratory test will illuminate. I think it needs to be pointed out that whooping cough is a real syndrome, with a largely forgotten, but unique characteristic that makes clinical diagnosis possible, and that we now realise, co-exists with subclinical infection.

I have studied 740 cases of clinically diagnosed whooping cough in the Keyworth Practice since 1977.2 The characteristic that distinguishes clinical pertussis is not the 'whoop', but the very long intervals (can be hours) without coughing, contrasting with the severe choking paroxysms that occur on average every 2 hours. Patients do not volunteer this information, indeed very few are aware of it until they have thought about it.

It is possible, but I think unlikely, that none of the oral fluid positive patients in Philipson's study had clinically diagnosable pertussis. If the right questions had been asked, the software may have learnt something, and very likely improved on the average clinician.

Pertussis is diagnosable if the characteristic symptoms are known and the right questions asked, or if the clinician hears the sound of a real whooping cough paroxysm and learns the tune, which few have had the opportunity to do, since the cough is inconveniently intermittent.

There is probably more danger from cases missed through lack of diagnostic skill than there is from the unknown number of subclinical cases, which, as opposed to missed cases, are not very important in the transmission of this disease that is still killing babies.

Doug Jenkinson,

DM, FRCGP, Retired GP, Gotham,

Nottingham NG11 OHT.

E-mail: dougjenkinsonabtinternet.com

\section{REFERENCES}

1. Philipson K, Goodyear-Smith F, Grant CC, et al. When is acute persistent couch in school-age children and adults whooping cough? A prospective case series study. Br J Gen Pract 2013; DOI: 10.3399/bjgp13X670705.

2. Jenkinson D. Natural course of 500 consecutive cases of whooping cough: a general practice population study. BMJ 1995; 310(6975): 299-302.

DOI: 10.3399/bjgp13X673658 